\title{
Handelt de huisarts bij ouderen anders dan de NHG-Standaard Incontinentie voor urine adviseert? En zo ja, waarom?
}

\author{
TAM Teunissen, WJHM van den Bosch, C van Weel, ALM Lagro-Janssen
}

\begin{abstract}
Inleiding
Urine-incontinentie (UI) is een veel voorkomend probleem bij ouderen, zowel bij mannen als vrouwen. Slechts de helft van de patiënten zoekt hulp bij de huisarts. Patiënten die wel hulp zoeken, ervaren de incontinentie als ernstiger, hebben er meer hinder van in het dagelijks leven en hebben langer klachten. Belangrijkste redenen om niet te gaan, zijn dat de patiënt het urineverlies niet ernstig genoeg vindt, of vindt dat het bij de leeftijd hoort en er toch niets aan te doen is. ${ }^{1}$ Conservatieve behandelingen, zoals bekkenbodemspieroefeningen en blaastraining, zijn echter ook bij ouderen succesvol gebleken. ${ }^{2}$ Deze bevinding is belangrijk, want UI is bij ouderen een van de belangrijkste voorspellers voor opname in een verpleegtehuis. ${ }^{3}$ Bovendien beïnvloedt incontinentie de kwaliteit van leven en is het verantwoordelijk voor een substantieel deel van de kosten in de gezondheidszorg. ${ }^{4}$ Het geschatte jaarlijks verbruik van incontinentiemateriaal is 85
\end{abstract}

\section{Samenvatting}

Teunissen TAM, Van den Bosch WJHM, Van Weel C, Lagro-Janssen ALM. Handelt de huisarts bij ouderen anders dan de NHGStandaard Incontinentie voor urine adviseert? En zo ja, waarom? Huisarts Wet 2008;51(2):70-5.

Doel Achterhalen wanneer en waarom huisartsen bij ouderen anders handelen dan de NHG-Standaard Incontinentie voor urine adviseert.

Methode Het onderzoek maakt deel uit van een groter onderzoek naar urine-incontinentie (UI) bij ouderen. Wij nodigden ouderen met ongecompliceerde UI die daarvoor niet eerder behandeld waren maar wel behandeld wilden worden, uit om naar hun eigen huisarts te gaan. Deze vulde na elk consult op een zelfregistratieformulier in in hoeverre hij de richtlijnen uit de NHGStandaard Urine-incontinentie had gevolgd. De onderzoeker besprak later met de huisartsen de redenen waarom zij van de standaard waren afgeweken.

Resultaten In totaal bezochten 19 mannen en 71 vrouwen hun huisarts. Bij de anamnese, het lichamelijk onderzoek en het urineonderzoek hield deze zich op alle punten aan de standaard. Bij de behandeling echter week de huisarts wel af van de standaard. Een zesde van de mannen en vrouwen zag af van behandeling omdat ze de ernst van de UI niet vond opwegen tegen de gevraagde inspanning voor de oefentherapie. Als er sprake miljoen euro, zieken- en verpleegtehuizen niet meegerekend. ${ }^{5}$ Het ontwikkelen van richtlijnen is een algemeen geaccepteerde methode om de kwaliteit van de hulpverlening te verhogen en heeft de laatste decennia steeds meer ingang gevonden - de NHGStandaard Incontinentie voor urine is er één van. ${ }^{6}$ Dat betekent echter niet automatisch dat men die richtlijnen ook daadwerkelijk toepast. Het is niet denkbeeldig dat de genoemde standaard in de praktijk soms moeilijk toepasbaar is, omdat hij in hoofdzaak gericht is op vrouwen van middelbare leeftijd en de prevalentie van UI juist bij ouderen het hoogst is. ${ }^{7}$

Dat UI bij ouderen zo vaak voorkomt, maakt een goede implementatie van de richtlijnen in deze groep extra belangrijk. Daartoe moet men echter weten hoe huisartsen de standaard in de dagelijkse praktijk toepassen en in hoeverre zij daarbij mogelijke hindernissen ondervinden. Omdat over dit laatste niets bekend was, hebben wij dit onderzoek opgezet. Onze onderzoeksvraag was:

was van comorbiditeit ervoeren zowel de huisarts als de patiënt de UI als meer complex, ook al omdat zij moesten kiezen welk medisch probleem de voorkeur kreeg. De huisartsen vonden met name gemengde incontinentie te complex en te tijdrovend om zelf te begeleiden.

Conclusie De NHG-Standaard Incontinentie voor urine is goed toepasbaar bij ouderen als het gaat om de anamnese, het lichamelijk onderzoek en het urineonderzoek, maar voor de behandeling geldt dat minder. De drie voornaamste redenen voor dat laatste zijn dat de patiënt de behandeling niet de inspanning waard vindt, dat patiënt en huisarts vanwege comorbiditeit moeten kiezen welke aandoening de voorkeur krijgt, en dat de huisarts de behandeling van UI bij ouderen complex en tijdrovend vindt.

Universitair Medisch Centrum St Radboud, vakgroep Huisartsgeneeskunde, afdeling Vrouwenstudies Medische Wetenschappen, Postbus 9101, 6500 HB Nijmegen: dr. T.A.M. Teunissen, huisarts, prof.dr. A.L.M. LagroJanssen, huisarts, hoogleraar Huisartsgeneeskunde/vrouwenstudies; vakgroep Huisartsgeneeskunde, prof.dr. W.J.H.M van den Bosch, huisarts, hoogleraar Huisartsgeneeskunde/Continuïteit van zorg, prof.dr. C. van Weel, huisarts, hoogleraar-directeur.

Correspondentie: D.Teunissen@hag.umcn.nl.

Mogelijke belangenverstrengeling: niets aangegeven 
Wat is bekend?

Urine-incontinentie is een frequent voorkomend probleem bij ouderen

Oefentherapie is ook bij ouderen effectief.

Wat is nieuw?

- Ouderen met incontinentie zijn minder gemotiveerd voor oefentherapie

- Comorbiditeit leidt zowel voor de arts als voor de patiënt tot prioritering

De huisarts ervaart de behandeling van urine-incontinentie bij ouderen als complex en tijdrovend.

handelt de huisarts bij ouderen anders dan de NHG-Standaard Incontinentie voor urine adviseert, en zo ja waarom?

\section{Methoden}

Ons onderzoek maakte deel uit van een grootschalig cross-sectioneel onderzoek naar het voorkomen van urine-incontinentie bij ouderen, uitgevoerd in het Oost-Nederland tussen januari 1999 en januari 2002. Wij gingen daarbij uit van de eerste versie van de NHG-Standaard Incontinentie voor urine ${ }^{6}$ en gebruikten dezelfde definitie van UI als deze standaard. De onderzoekspopulatie was afkomstig uit de huisartsenpraktijken verbonden aan het Nijmeegse Monitoring Project, een academisch registratienetwerk van de afdeling Huisartsgeneeskunde van het UMC St Radboud. ${ }^{8}$ Dit project omvat 9 volledig gecomputeriseerde praktijken met in totaal 46.500 patiënten en 20 huisartsen.

Alle zelfstandig wonende patiënten van zestig jaar en ouder uit de deelnemende praktijken kregen een vragenlijst thuisgestuurd, en na twee weken een herinnering. Patiënten die niet in staat waren om een vragenlijst in te vullen, zoals demente of ernstig zieke patiënten, bleven buiten het onderzoek. De patiënten die op de vragenlijst hadden aangegeven dat ze incontinent waren en wilden meedoen aan het vervolgonderzoek namen wij thuis een interview af. Het onderzoek richtte zich op ongecompliceerde UI zoals de NHG-Standaard die beschrijft. Patiënten met een neurologische of ernstig psychiatrische aandoening of die in het verleden een mislukte operatie voor urine-incontinentie hadden ondergaan, sloten wij uit. Alle patiënten die in het verleden nog geen uitgebreide conservatieve therapie hadden gehad en die wel behandeld wilden worden, vroegen wij de eigen huisarts te consulteren (figuur). De onderzoeksassistente maakte voor hen een afspraak.

De deelnemende huisartsen kregen voorafgaand aan het onderzoek een nascholing specifiek gericht op de richtlijnen van de standaard en de daarbij behorende instructies voor oefentherapie. We deden dit omdat we wilden uitsluiten dat de huisartsen door een gebrek aan kennis zouden afwijken van de standaard. Tijdens het interview dat wij met de patiënten hadden voordat ze naar de huisarts gingen, verzamelden wij gegevens over leeftijd, geslacht, civiele status, opleiding en duur van de klachten. Het type incontinentie bepaalden wij met de volgende vragen:" "Ver- liest u urine bij drukverhogende momenten zoals niezen, springen of hoesten?' en: 'Heeft u zo'n sterke aandrang dat u urine verliest voordat $u$ het toilet bereikt?' We spraken van stressincontinentie als de patiënt urine verloor bij drukverhogende momenten, maar niet bij sterke aandrang. Verloor de patiënt urine bij sterke aandrang, maar niet bij drukverhogende momenten, dan noemden we dat urge-incontinentie. Bij gemengde incontinentie waren beide componenten aanwezig.

De ernst van de UI scoorden we op de PRAFAB-schaal (protection, amount, frequency, adjustment, body image). ${ }^{10}$ De schaal bevat vragen over het gebruik van incontinentiemateriaal, de hoeveelheid urineverlies per keer, de frequentie van het urineverlies en de beperkingen in het dagelijks leven. De PRAFAB-score kan verdeeld worden in de categorieën mild (1-7 punten), matig (8-13 punten) en ernstig (14-20 punten).

Gegevens over de toepasbaarheid van de standaard verkregen we met behulp van zelfregistratieformulieren. Een zelfregistratieformulier is een gevalideerde methode om de implementatie van bestaande richtlijnen te meten. ${ }^{11}$ Het in dit onderzoek gebruikte formulier bevatte negentien items die relevant zijn voor een optimale behandeling van UI, vastgesteld door een panel van deskundigen. De huisartsen registreerden na elk consult op het zelfregistratieformulier of ze deze negentien items wel of niet hadden opgevolgd. Na het consult controleerde de onderzoeker (TT) de ingevulde formulieren op compleetheid. Indien hij de richtlijnen niet had opgevolgd, stelde de huisarts de redenen daarvoor op schrift. De onderzoeker had daarna met iedere deelnemende huisarts een interview om meer in de diepte te vragen naar de motieven om van de richtlijnen af te wijken. De interviews werden volledig uitgeschreven

\section{Statistische analyse}

Per relevant item analyseerden wij in hoeverre de 20 deelnemende huisartsen de standaard toepasten bij mannelijke en vrouwelijke patiënten. Een huisarts scoorde goed op een item indien hij het toepaste bij $80 \%$ of meer van de patiënten, matig bij $50 \%$ tot $80 \%$ van de patiënten en slecht bij minder dan $50 \%$ van de patiënten. Een tweede onderzoeker (ALJ) analyseerde eveneens de redenen om van de standaard af te wijken. Vervolgens groepeerden wij de redenen in thema's

\section{Resultaten}

Van de 56 mannelijke en 314 vrouwelijke geïnterviewden had respectievelijk $27 \%$ en $50 \%$ geen belangstelling om de huisarts te bezoeken en het urineverlies in kaart te brengen. Negentien mannen (33\%) en 71 vrouwen (22\%) bezochten de huisarts wél, zodat wij beschikten over in totaal 91 zelfregistratieformulieren. Deze formulieren hebben wij voor beide seksen apart geanalyseerd, omdat de pathofysiologie van UI bij mannen verschilt van die bij vrouwen. Zoals verwacht vonden wij verschillen tussen beide seksen voor wat betreft het type incontinentie, maar ook bleek dat de incontinentie bij de deelnemende vrouwen ernstiger was dan bij de mannen (tabel 1). 


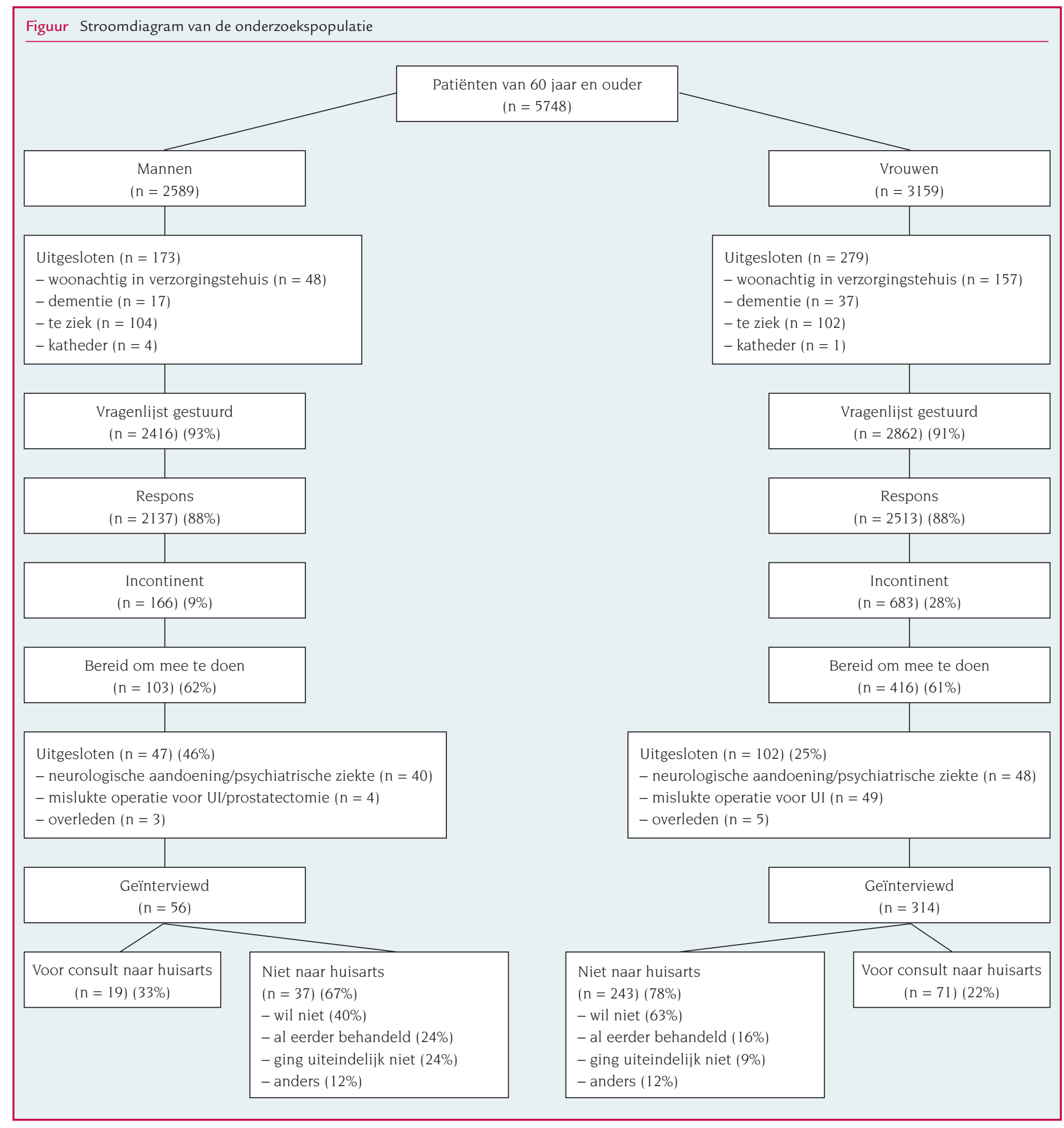

De huisartsen scoorden goed op alle items die te maken hadden met de anamnese, het lichamelijk onderzoek en het urineonderzoek, maar de ingestelde therapie week vaak af van de richtlijnen (tabel 2). Of de therapieën die de deelnemende huisartsen instelden ook onderling duidelijk verschilden, konden wij niet goed vaststellen omdat het aantal patiënten per huisarts daarvoor te klein was. Bij 4 van de 19 mannen en 11 van de 71 vrouwen zag de huisarts af van behandeling omdat de patiënt de moeite die de therapie kostte niet vond opwegen tegen de ernst van de incontinentie. Met name de frequentie waarmee de bekkenbodemspieroefeningen gedaan moeten worden en de angst om helemaal nat te worden gedurende blaastraining waren voor hen zwaarwegende redenen.

Ook comorbiditeit, indien aanwezig, kon reden zijn om de standaard niet te volgen. In dat geval moeten arts en patiënt kiezen welke aandoening prioriteit krijgt. Daarbij was niet zozeer het type comorbiditeit van belang als wel het aantal en de ernst van de aanwezige aandoeningen.

De NHG-Standaard stimuleert huisartsen zelf hun patiënten te 
instrueren en te begeleiden bij het starten van bekkenbodemspieroefeningen (in het geval van stressincontinentie) of blaastraining (in het geval van urge-incontinentie). De deelnemende huisartsen vonden dit echter lastig en tijdrovend. Het was voor hen een belangrijke reden om 6 van de 32 vrouwen met stressincontinentie en 12 van de 25 vrouwen met gemengde incontinentie naar de fysiotherapeut te verwijzen zonder zelf enige instructie te geven. Er waren ook andere redenen:

\begin{tabular}{|c|c|c|}
\hline Geslacht & $\begin{array}{l}\text { Vrouwen } \\
(n=71)\end{array}$ & $\begin{array}{l}\text { Mannen } \\
(n=19)\end{array}$ \\
\hline Leeftijd (gemiddeld) & $70(\mathrm{SD} 5,7)$ & $72(\mathrm{SD} 7,9)$ \\
\hline \multicolumn{3}{|l|}{ Burgerlijke staat } \\
\hline - Gehuwd, samenwonend & 52 & 16 \\
\hline - Ongehuwd & 1 & - \\
\hline - Weduwe/weduwnaar & 15 & 3 \\
\hline - Gescheiden & 3 & - \\
\hline \multicolumn{3}{|l|}{ Opleiding } \\
\hline - Lagere school, LBO & 43 & 8 \\
\hline - Mulo, MMS, MBO & 18 & 8 \\
\hline \multicolumn{2}{|l|}{ Ernst } & 3 \\
\hline $\begin{array}{l}\text { Ernst } \\
- \text { Licht }\end{array}$ & 15 & 10 \\
\hline - Matig & 43 & 8 \\
\hline - Ernstig & 13 & 1 \\
\hline \multicolumn{3}{|l|}{ Type } \\
\hline - Stress & 32 & 4 \\
\hline - Urge & 8 & 10 \\
\hline - Gemengd & 31 & 2 \\
\hline - Anders & - & 3 \\
\hline \multicolumn{3}{|l|}{ Biikomende pathologie } \\
\hline - Cystocele & 29 & - \\
\hline - Descensus uteri & 7 & - \\
\hline - Vaginale atrofie & 9 & - \\
\hline - Vergrote prostaat & - & 6 \\
\hline
\end{tabular}

- de huisarts was van mening dat de fysiotherapeut veel meer tijd aan de patiënt kon spenderen en daardoor betere zorg kon leveren;

$\checkmark$ de patiënt was niet in staat om de bekkenbodem aan te spannen;

- de huisarts meende dat gemengde incontinentie een complexe aandoening is, die beter door een fysiotherapeut met speciale expertise kan worden behandeld;

- de huisarts had gunstige ervaringen met verwijzing van patiënten.

De NHG-Standaard adviseert om patiënten met gemengde incontinentie te laten starten met blaastraining, later gevolgd door bekkenbodemspieroefeningen. Desondanks startten tien vrouwen met gemengde incontinentie met blaastraining en bekkenbodemspieroefeningen tegelijk en kregen anderen alleen blaastraining of alleen bekkenbodemspieroefeningen. De belangrijkste reden hiervoor was dat dit de behandeling voor arts en patiënt minder complex maakte.

Twee vrouwen met urge-incontinentie kregen medicijnen in combinatie met blaastraining, hoewel de NHG-Standaard adviseert eerst met blaastraining te starten. Deze huisarts week van de standaard af omdat hij goede ervaringen had met de gecombineerde therapie.

Ook het follow-upbeleid was veel gevarieerder dan de 6 of 12 weken die de richtlijnen adviseren. De huisarts maakte doorgaans geen controleafspraak met patiënten die verwezen waren naar de fysio-

\begin{tabular}{|c|c|c|c|c|}
\hline \multirow{2}{*}{$\begin{array}{l}\text { Item van standaard } \\
\text { Anamnese }\end{array}$} & \multicolumn{2}{|c|}{ Mannen $(n=19)$} & \multicolumn{2}{|c|}{ Vrouwen $(n=71)$} \\
\hline & & & & score \\
\hline \multicolumn{5}{|l|}{$\begin{array}{l}\text { Anamnese } \\
\text { - Type }\end{array}$} \\
\hline - Urineverlies tijdens drukverhogende momenten? & $100 \%$ & goed & $100 \%$ & goed \\
\hline - Urineverlies bij sterke aandrang? & $100 \%$ & goed & $100 \%$ & goed \\
\hline - Continu verlies van urine? & $100 \%$ & goed & $97 \%$ & goed \\
\hline \multicolumn{5}{|l|}{ - Ernst } \\
\hline - Wordt er incontinentiemateriaal gebruikt? & $100 \%$ & goed & $93 \%$ & goed \\
\hline - Wat is de frequentie van het urineverlies? & $100 \%$ & goed & $100 \%$ & goed \\
\hline - Wat zijn de gevolgen van het urineverlies? & $100 \%$ & goed & $90 \%$ & goed \\
\hline \multicolumn{5}{|l|}{ - Relevante factoren } \\
\hline - Medicatiegebruik & $95 \%$ & goed & $97 \%$ & goed \\
\hline - Operaties in het verleden & $95 \%$ & goed & $100 \%$ & goed \\
\hline - Mobiliteit & $95 \%$ & goed & $96 \%$ & goed \\
\hline - Neurologische aandoening & $95 \%$ & goed & $100 \%$ & goed \\
\hline $\begin{array}{l}\text { - Pijn bij de mictie } \\
\text { - Veranderd mictiepatroon }\end{array}$ & $\begin{array}{l}100 \% \\
90 \%\end{array}$ & $\begin{array}{l}\text { goed } \\
\text { goed }\end{array}$ & $\begin{array}{l}91 \% \\
87 \%\end{array}$ & $\begin{array}{l}\text { goed } \\
\text { goed }\end{array}$ \\
\hline Urineonderzoek (nitriet of sediment) & $100 \%$ & goed & $98 \%$ & goed \\
\hline \multicolumn{5}{|l|}{ Lichamelijk onderzoek } \\
\hline - Vaginaal toucher & - & - & $94 \%$ & goed \\
\hline - Beoordeling spierkracht bekkenbodem & - & - & $85 \%$ & goed \\
\hline - Rectaal toucher & $84 \%$ & goed & - & \\
\hline \multicolumn{5}{|l|}{ Behandeling } \\
\hline - Oefentherapie bij stressincontinentie & $75 \%$ & matig & $68 \%$ & matig \\
\hline - Blaastraining bij urge-incontinentie & $60 \%$ & matig & $80 \%$ & goed \\
\hline - Eerst blaastraining later gecombineerd met oefentherapie bij gemengde incontinentie & $50 \%$ & matig & $16 \%$ & slecht \\
\hline \multicolumn{5}{|l|}{ Follow-up } \\
\hline - Bij stressincontinentie (controle na 6 weken) & & matig & $22 \%$ & slecht \\
\hline - Bij urge-incontinentie (controle na 6 tot 12 weken) & $60 \%$ & matig & $88 \%$ & goed \\
\hline - Bij gemengde incontinentie (controle na 6 weken) & $0 \%$ & slecht & $52 \%$ & matig \\
\hline
\end{tabular}


therapeut. Een derde van de huisartsen was, onafhankelijk van het type incontinentie en het geslacht van de patiënt, gewend om deze pas na langere termijn terug te bestellen. Zij vonden dat het effect van de behandeling pas na langere termijn goed te beoordelen is en vonden tussentijdse controle daarom niet zinvol.

\section{Beschouwing}

De NHG-Standaard Incontinentie voor urine is goed toepasbaar, ook bij oudere patiënten, als het gaat om anamnese, lichamelijk onderzoek en urineonderzoek. In dit onderzoek ging het ons met name om die toepasbaarheid, niet om de kennis van de huisarts. Daarom hebben we de deelnemende huisartsen voorafgaand aan het onderzoek een specifieke nascholing gegeven in de richtlijnen van de standaard. Ons is in eerder onderzoek gebleken dat de kennis van de huisarts over de diagnostiek van UI bij ouderen vaak tekortschiet. ${ }^{12}$ Het is daarom te verwachten dat het handelen van 'ongetrainde' huisartsen nog veel vaker zal afwijken van de standaard dan wij in dit onderzoek vonden.

Opvallend is dat een zesde van de mannen en vrouwen aangaf dat de impact van de incontinentie niet opweegt tegen de moeite die het kost om de oefeningen uit te voeren en vol te blijven houden. Deze patiënten besloten daarom, nadat zij volledig geïnformeerd waren over de oefentherapie, er niet mee te starten. Opvallend is ook dat een derde van de behandelde patiënten niet terugkwam voor de afgesproken controle. Het is de vraag of zij de therapie wel hebben afgemaakt of er überhaupt aan begonnen zijn. Men moet daarbij bedenken dat deze patiënten voorafgaand aan het onderzoek thuis geïnterviewd waren, uitleg over de behandelingsmogelijkheden hadden gekregen en uitgenodigd waren om voor inventarisatie en behandeling van de incontinentie naar de huisarts te gaan, en dus behoorden tot de minderheid van geïnterviewde patiënten die besloot aan het onderzoek mee te doen. Maar zelfs van deze gemotiveerde groep gaf een deel dus uiteindelijk aan dat ze de incontinentie niet ernstig genoeg vonden om een intensievere behandeling te rechtvaardigen. De objectieve ernst van de incontinentie, gemeten met een gevalideerde schaal, verschilde in de groep die geen behandeling wilde niet van de groep die wél behandeling wilde. Eerder onderzoek ${ }^{13,14}$ heeft uitgewezen dat ouderen minder gemotiveerd zijn voor therapie en minder grote verwachtingen hebben over hun gezondheid. Ook bij de huisarts is de motivatie om ouderen een behandeling voor UI aan te bieden vaak niet groot, met name omdat hij pessimistisch is over het effect van de behandeling en over de tijdsinvestering die nodig is om een patiënt goed te begeleiden. ${ }^{12}$

Naast deze motivatieproblemen - ouderen hebben minder verwachtingen aangaande hun gezondheid - is er bij veel ouderen ook sprake van comorbiditeit. Dit maakt de UI complexer en kan de patiënt en de huisarts voor de noodzaak stellen te beslissen welk probleem de prioriteit krijgt. Zowel de patiënt als de dokter zien daarbij de UI niet altijd als het ernstigste probleem, en zij kunnen in goed onderling overleg uiteindelijk besluiten om de voorkeur te geven aan andere gezondheidsproblemen. ${ }^{15}$

De huisartsen verwezen ongeveer eenvijfde van de vrouwen met

\section{Abstract}

Teunissen TAM, Van den Bosch WJHM, Van Weel C, Lagro-Janssen ALM. Does the GP treat elderly people differently than is advised in the NHG Standard for Incontinence? If so, why? Huisarts Wet 2008;51(2):70-5.

Aim To discover when and why GPs deal with patients differently than is advised in the NHG Standard for Urine Incontinence.

Method The investigation is part of a larger study of urine incontinence (UI) in the elderly. We invited elderly people with uncomplicated UI, who had not previously received treatment for the condition but did wish to be treated, to go to their GP. After each consultation the GP filled in a self-registration form recording the extent to which he had followed the guidelines contained in the NHG Standard for Urine Incontinence. The researcher later discussed with the GPs why they had deviated from the Standard.

Results A total of 19 men and 71 women visited their GP. During the anamnesis, the physical examination and the urine check the GPs kept to the Standard on all points. However the GPs did sometimes deviate from the Standard in the treatment phase. One sixth of the men and women decided not to undergo treatment because they regarded the UI not sufficiently severe to merit the effort they would be required to make in the exercise therapy. When it was possible to identify comorbidity, both the GP and the patient regarded the UI as more complex, also because they had to choose which medical problem was to be preferentially treated. The GPs found mixed incontinence in particular as too complex and time-consuming to treat themselves. Conclusion The NHG Standard for Urine Incontinence applies well to elderly patient where anamnesis, physical examination and the urine check are concerned, but applies to a lesser extent in the treatment. The three main reasons for this are: the patient finds the treatment not worth the effort; because of comorbidity patient and doctor must choose which condition is given preferential treatment; and the GP finds the treatment of UI in the elderly complex and time-consuming.

stressincontinentie en eenderde van de vrouwen met gemengde incontinentie naar de fysiotherapeut. Vooral bij gemengde incontinentie hadden zij het idee dat hun expertise tekortschoot en dat de behandeling ingewikkeld en tijdrovend zou zijn. Goede begeleiding is essentieel om ouderen te motiveren en gemotiveerd te houden. Huisartsen vinden het moeilijk om ouderen adequaat te instrueren, en ze hebben bij patiënten met UI bovendien vaak goede ervaringen met verwijzingen naar de fysiotherapeut. Ook huisartsen die besluiten om de aanbevolen behandeling zelf te geven, vinden de behandeling van gemengde incontinentie $(40 \%$ van de gevallen van UI bij ouderen) complex en tijdrovend. Voor hen is dit reden om de adviezen van de standaard aan te passen in een meer patiëntgerichte richting.

Niet alleen in de behandeling maar ook in de follow-up volgden de huisartsen de adviezen niet volledig op. Huisartsen die de patiënt hadden verwezen naar de fysiotherapeut maakten geen controle- 
afspraak. Toch zou het nut hebben de patiënt te vragen om na drie maanden terug te komen als de fysiotherapeutische behandeling geen of onvoldoende effect zou hebben. Dit zou de gelegenheid bieden om andere behandelingsopties te bespreken.

\section{Vergelijking met de eerste herziening van de standaard}

Bij ons onderzoek hebben wij de eerste versie van de NHG-Standaard Incontinentie voor urine gebruikt. Inmiddels is van deze standaard een eerste herziening verschenen. ${ }^{16}$ De adviezen rond de negentien items van ons onderzoek zijn echter nagenoeg ongewijzigd gebleven. De herziene versie ziet het instrueren en begeleiden van oefentherapie niet meer primair als taak van de huisarts en laat het aan deze over om de begeleiding zelf te doen of naar een fysiotherapeut te verwijzen. De uitkomsten van ons onderzoek zullen ook op de herziene standaard van toepassing zijn, behalve wat betreft de verwijzingen naar de fysiotherapeut.

\section{Sterke en zwakke punten}

Een sterk punt van ons onderzoek is de combinatie van kwalitatieve gegevens (waarom wijken huisartsen af van de standaard) met kwantitatieve gegevens: en hoe vaak doen ze dat dan?

Een beperking is het kleine aantal patiënten, met name mannen. Omdat we ons richtten op ongecompliceerde UI, zoals ook de NHG-Standaard dat doet, moesten wij meer dan de helft van de potentiële mannelijke deelnemers uitsluiten, meestal vanwege een neurologische aandoening. Een andere beperking is dat een groot gedeelte van de patiënten niet bereid was de huisarts te bezoeken omdat ze de incontinentie niet ernstig genoeg vonden. Dit onderschrijft de bevinding uit eerder onderzoek ${ }^{13,14}$ dat ouderen minder gemotiveerd zijn voor therapie. Doordat het aantal patiënten klein was, moeten we voorzichtig zijn bij het generaliseren van onze uitkomsten.

\section{Conclusie}

Een aanzienlijk aantal ouderen met UI vindt dat de ernst van hun klachten niet opweegt tegen de belasting van de oefentherapie. Dit doet vermoeden dat de invloed van UI op de kwaliteit van leven niet dramatisch is. Wanneer de oudere patiënt dan afziet van de behandeling, is het wel belangrijk op welke manier de huisarts die heeft aangeboden en uitgelegd. Uit ons eerdere onderzoek blijkt immers dat de kennis en de motivatie om UI bij ouderen te diagnosticeren en te behandelen, bij huisartsen onvoldoende aanwezig zijn. ${ }^{12}$

Maar misschien is het ook heel terecht dat zowel huisarts als patiënt afzien van therapie en aan mogelijke andere gezondheidsproblemen de voorkeur geven. Meer onderzoek is nodig om hierop een antwoord op te krijgen. Het is van belang om een goede kwaliteit van zorg na te streven voor ouderen met UI, maar niet minder belangrijk is het onnodige medicalisering te voorkomen. Bovendien is het logisch dat huisartsen de behandeling van UI bij ouderen soms minder tijdrovend en ingewikkeld maken dan de adviezen luiden, én dat zij verwijzen naar de fysiotherapeut om de begeleiding te intensiveren. Deze handelwijze is inmiddels opgenomen in de herziene standaard. Het zou wel navolgenswaardig zijn patiënten aan te raden de huisarts opnieuw te bezoeken als de incontinentie na drie maanden oefentherapie niet is verbeterd, en dan samen andere behandelingsopties te bespreken. De lacunes in de kennis van de huisarts op het gebied van UI zullen gedicht moeten worden door nascholingsprogramma's.

\section{Literatuur}

1 Teunissen TAM, Van Weel C, Lagro-Janssen ALM. Urine-incontinentie bij zelfstandig wonende ouderen: wie zoekt er hulp bij de huisarts. Huisarts Wet 2007;50:4-10

2 Teunissen TAM, De Jonge A, Van Weel C, Lagro-Janssen ALM. Treating Urinary Incontinence in elderly-conservative measures that work: A systematic review. J Fam Pract 2004;53:25-32.

3 Holrovd-Leduc JM, Metha KM, Covinsky KE. Urinary incontinence and its association with death, nursing home admission, and functional decline. J Am Geriatr Soc 2004;52:712-8.

4 Coyn KS, Zhou Z, Thompson C, Versi E. The impact on health-related quality of life of stress, urge and mixed Urinary Incontinence. BJU inter 2003;92:73-15.

5 CVZ. Care rate1995-1999. Amstelveen: CVZ, 2000.

6 Lagro-Janssen ALM, Breedveldt Boer HP, Van Dongen JJ. NHG-Standaard Incontinentie voor urine. Huisarts Wet 1995;38:71-80.

7 Teunissen TAM, Van Weel C, Lagro-Janssen ALM. De prevalentie van urine en ontlasting bij zelfstandig wonende ouderen in Nijmegen, januari 1999-juli 2001. Ned Tijdschr Geneeskd 2006;150:2430-4

8 Van Weel C, Smith H, Beasly JW. Family practice research networks. Experiences from 3 countries. J Fam Pract 2000;49:938-43.

9 Lagro-Janssen ALM, Debruyne FMJ, Van Weel C. Value of patient's case history in diagnosing urinary incontinence in general practice. Br J Urology 1991;76:569-72.

10 Vierhout ME. Meting van ongewild urineverlies bij vrouwen. Ned Tijdschr Geneeskd 1990;134:1837-9.

11 Grol R. Implementing guidelines in general practice care. Quality in Health Care 1992; 1:184-91

12 Teunissen D, Van den Bosch W, Van Weel C, Lagro-Janssen T. Urinary incontinence in the elderly: attitudes and experiences of general practitioners. A focus group study. Scand J Prim Health Care 2006;24:56-61.

13 Horrocks S, Somerset M, Stoddart H, Peters TJ. What prevents older people from seeking treatment for urinary incontinence? A qualitative exploration of barriers to the use of community continence services. Fam Pract 2004;21:689-96.

14 Shaw C, Tansey R, Jackson C, Hyde C, Allan R. Barriers to help seeking in people with urinary symptoms. Fam Pract 2001;18:48-52.

15 Flood CG, Drutz HP. Perception of urinary incontinence as a health care problem in women. Int Urogynecol J 1995;6:89-94.

16 Lagro-Janssen ALM, Breedveldt Boer HP, Van Dongen JJAM, Lemain TJJ, Teunissen D. NHG-Standaard Incontinentie voor urine. Huisarts Wet 2006:49:501-10. 